\title{
Developing Integrated Pedagogical Approaches in Play Pedagogy: Malaysian Experiences
}

\author{
Norsuhaily Abu Bakar ${ }^{1}$, Normadiah Daud ${ }^{2}$, Nadhirah Nordin $^{2} \&$ Abdul Hakim Abdullah ${ }^{2}$ \\ ${ }^{1}$ Faculty of Applied Social Science, Universiti Sultan Zainal Abidin, Malaysia \\ ${ }^{2}$ Faculty of Islamic Contemporary Studies, Universiti Sultan Zainal Abidin, Malaysia \\ Correspondence: Norsuhaily Abu Bakar, Faculty of Applied Social Science, Universiti Sultan Zainal Abidin, \\ Malaysia. E-mail: norsuhaily@unisza.edu.my
}

$\begin{array}{lc}\text { Received: October 9, } 2014 & \text { Accepted: November 17, } 2014 \quad \text { Online Published: January 14, } 2015 \\ \text { doi:10.5539/ass.v11n4p234 } & \text { URL: http://dx.doi.org/10.5539/ass.v11n4p234 }\end{array}$

\begin{abstract}
This paper examines contemporary developments in play and pedagogy in early childhood education settings, drawing on Malaysian policies and international play scholarship. The study explores and analyses some of the challenges inherent to incorporating play into classroom practice, which is occurring in four types of preschool classroom settings in Malaysia. It investigates the implementation of play in each of these settings. Established principles about play and learning are reified in many curriculum guidelines, alongside recommendations for the role of adults in linking play provision with their pedagogical strategies. Play is also located within contemporary discourses about quality and effectiveness, with a specific focus on 'educational' play (Wood, 2010). Although policy texts and policy-oriented research have provided positive validations for play as integral to 'effective practice', there remain significant challenges in conceptualizing the play-pedagogy relationship. Linking play with defined educational outcomes and effectiveness agendas also raises questions about the regulation of play through dominant policy discourses and practices. Drawing on critical and post developmental theories, some of the key principles underpinning play and pedagogy are scrutinized here. It will be argued that some of the essential truths about play can also be seen as myths, which need to be contested in the light of contemporary concerns with diversity, power and control and how these relate with educational settings.
\end{abstract}

Keywords: play-pedagogy, early childhood, Malaysian contexts

\section{Introduction}

Theorists and researchers paint a convincing picture of the importance of play to children's learning and development (Balter \& Tamis-LeMonda, 2006; Roskos \& Christie, 2010). As discussed by Little and Wyver (2008, p. 33), "within the early childhood field, play has long been acknowledged as an important context for children's learning and development. Play is a significant aspect of children's lives, reflecting their social and cultural contexts". However, enrolling children into preschools that advocate learning through play is not a straightforward task.

Kamogawa, (2010) makes the strong point, that for Malaysia to become an advanced nation by 2020, it is valuable to have this focus on attaining Universal Primary Education (UPE) in early childhood, as has been the case from the late-1990s to the early 2000s. The Child Care Center Act 1984 [308 Act] (2006) passed against a background of rising workforce participation by women, and an establishment of basic child care infrastructure. Nevertheless, compared with primary education, which was also becoming universal, in 2006 preschool education was still not fully available (Tejima, 2006).

A further challenge for the early childhood sector itself is to enhance the educational background and quality of preschool teachers as stated in $10^{\text {th }}$ Malaysia Plan (2011-2015). To improve the quality of preschool teachers, the qualifications for their appointment will be raised to a diploma or a bachelor degree. This rise in qualification will have a profound impact on the Early Childhood sector, for example it means that the Government will now implement measures to establish teaching as a profession of choice (Economic Planning Unit, 2010).

Currently in Malaysia we have greater access to and higher numbers of students in early education, as well as dropping teacher student ratio, and we have the MOE committed to raising teacher education levels. However an area of concern that also concerns education experts relates to academic approaches that put too much pressure 
on young children to succeed without providing opportunities for them to actively construct knowledge (Kagan \& Kauerz, 2009). There is no argument that early childhood programs need to continue their focus on cognitive development but research demonstrates that there must also be a focus on socioemotional development, if best practices are to be achieved.

From professional experience within early childhood education centres in Malaysia the researcher found that learning through play has many challenges. For example, many children in Malaysian preschools are being educated in a formal way. This "formal pedagogic world" does not allow for the needs of child development as advocated in the learning through play approach but it stresses an academic approach and more formal academic monitoring though testing. Furthermore, there also seems to be entrenched competition among the preschool providers, to attract "customers" and to show that their school is the best in educating children. These personal experiences link with research from two decades ago by Ling (1993) who concluded from her study that the most of the preschools in Malaysia used a variety of academic and formal curricula.

The implementation of the learning through play approach also faces the challenge of the lack of teachers' understanding of the tenets of child development, as evidenced through scholarly research and demonstrated good practice internationally, and which has pedagogic significance in what the MOE advocates for young children. The teachers are reported to have limited knowledge of how play should be implemented in classroom practice and some teachers fail to engage with the children whenever playtime is involved. Others implement play-based learning in formal teacher-centered activities. Indeed, many teachers are not aware of how their philosophical positioning impacts on the way they teach, an issue addressed within a bachelor level training degree. And yet another factor is the lack of resource provision for early childhood development and education. This situation leads to a lack of materials, suitable environments and sources created for play.

All of these problems combined have led to the development of the following research questions. These questions are designed to explore where play-based learning is employed and how valued play-based learning is by different stakeholders.

\section{Literature Review}

\subsection{Culture and Learning through Play}

The way that children learn through play is culturally specific as result of differences in childrearing beliefs, values, and practices. Play both influences and reflects the way children from different cultures learn. Most theorists and researchers in western cultures would agree with the previously described definition of play where play is enjoyable, have no extrinsic goals, no prescribed learning that must necessarily occur, is spontaneous and voluntary, involves active engagement on the part of the player, involves an element of make-believe.

Yet the challenge of how to interpret child's play and development differs from culture to culture. Even defining child's play and a child's other activities differ depending on one's culture. For example, many families with Asian ethnic cultural influences tend to see play and academic activity substantively, mutually exclusive of one another (Lang, 1997). In contrast, from an Italian perspective, as in the Reggio Emilia approach, there is little distinction between play and child's other activities, and rather a strong emphasis on social-interaction in child's play (Hewett, 2001). Many U.S. educators and researchers together with Euro-American perspectives strongly believe that child-initiated play and similar related experiences have an important bearing on the the child's development through his/her later academic experiences.

There is a cultural tendency of many families with Asian backgrounds to perceive child's play as a subject in itself rather than as a means for supporting academic experiences when the child becomes a kindergartner. Children tend to spend a great deal of their time in activities known as academically oriented experiences in their daily schedules (Takeuchi, 1994). These phenomena are highly valued and encouraged by the ethnic culture. Lang (1997) completed research on phenomenological interviews as well as field observations with Korean parents in Seoul, Korea and with Korean-American families in the New England, US area. The research found that these parents tended to strongly believe that academic activities are more highly valued than play, but within an academic activity the parents believe that children can enjoy it as a kind of play; "Academic activities are more important than play. Even if they are doing an academic work, they are still in a kind of play because they make it as a playful or fun study (interview with a Korean-American mother, Durham, NH, March 1997), (Lang, 1997).

\subsection{The Role of Teachers}

In the Bennett et al. (2009) study it was found that teachers who understood the importance of providing supportive frameworks for developing and accessing children's skills as players and learners, and encouraged 
children to follow their own interests and agendas, realized value in coming to understand the meaning of play in children's terms rather than in relation to their own predetermined learning objectives.

Bennett et al. (2009) question the view that exploring and discovering leads to learning. They argue that children need adults' help to make sense of their discoveries and to make links and connections between new discoveries and their existing knowledge. Repetitive play can also be a dilemma, in that adults are uncertain about when, or indeed whether, they should intervene to move the child on. This uncertainty is linked with a particular view of the child as a learner, and also of the role of adults in children's play. The belief that children cannot fail during play was also challenged by this study, as instances were observed of children being unable to pursue their goals during play because they lacked specific skills or knowledge.

Those participating in the study re-evaluated the adult's role during play. As regards role-play, the teachers held the view that this is the 'child's world' and, therefore, felt uncomfortable about intervening unless invited to do so by the children. Most teachers intervened in other sorts of play, particularly to support children's language or skills development.

It was also evident in the Bennett et al. study that, on occasions, the teachers' intentions for the play activity were not well matched or appropriate for the children. This could be either because the children had already achieved the learning intention, or because, while the play activity elicited a set of behaviors from the children, it did not seem to extend or develop their learning. Children's intentions during a play activity were sometimes at odds with those of the teacher, and this was problematic for the teachers. In one instance, children played dogs and babies, despite the fact that the teacher had set up the imaginative role-play area to encourage and facilitate play around the theme of birthday parties. In another setting, children played burglars and guard dogs in the class 'shop' (Bennett et al., 2009, p. 73). This research does not suggest that play is not valuable, nor that early years settings should introduce formal teaching. It does, however, encourage teachers to look more closely at the actual play experiences of children, and it acts as a catalyst for developing our thinking about how we should be planning for play, and about the role of adults in children's play.

Wood (2010) who was part of the Bennett et al. (2009) group found within her own study, that teachers understood the importance of seeing children's patterns of learning. Wood's own research highlighted how interactions could inform a teacher's pedagogy and curriculum planning (Wood, 2010).

In addition Broadhead's (2004) study of children's social and co-operative skills revealed possibilities for new reading and understanding of knowledge-power relations between children, and between children and adults and gives some insights to professional development for preschool teachers particularly. In looking at play through the sociocultural lens teachers are given opportunity to see that play is not simply enactments of the child's world, but are reflective of their understanding of the complexity of the worlds they inhabit.

In elaborating the role of teacher as 'playmate', the work of Wood (2010) also provides some insight into integrated approaches. According to her, adults are involved with children in planning for play and child-initiated activities, based on their observations and interactions. Planning and pedagogical decision-making are informed by children's choices, interests, capabilities and knowledge, which feed forward into further curriculum planning The teachers in the study by Bennett et al. (2009) translated their theories into practice through planning, organization, modifying the environment and through their intentions for learning. According to Hewett (2001), the teacher's role "centers on provoking occasions of discovery through a kind of alert, inspired facilitation and stimulation of children's dialogue, co-action, and co-construction of knowledge" (p. 97). Beatty (1998) describes the instrument used in her study of teaching and learning in classrooms; "where it is depending on user's goals it may be used to investigate relationships between teaching and learning and to encourage teachers to reflect on teaching practices" (Beaty, 1998, p. 1). This instrument has potential for modification and use in my current study, as teachers' reflection on their own practice is an important aspect of my research.

The teachers involved in these studies generally demonstrated a shift in understanding about their role in children's play, about when to intervene and when not to intervene, about their intentions for planning for play, and about the importance of sustained play. They came to understand how their observations of play could inform curriculum planning. Thus strategies can be adopted to support children's play and learning, and to maintain communication with the home, as demonstrated in the Reggio Emilia approach.

The term organizing and modifying the teaching and learning environment incorporates two key ideas that characterize early childhood education, (1) children's learn through positive relationship with adult teachers and other children; and (2) the learning context matters, referring to the indoor and outdoor environments, how the environments are organized, the materials and the equipment they contain. 


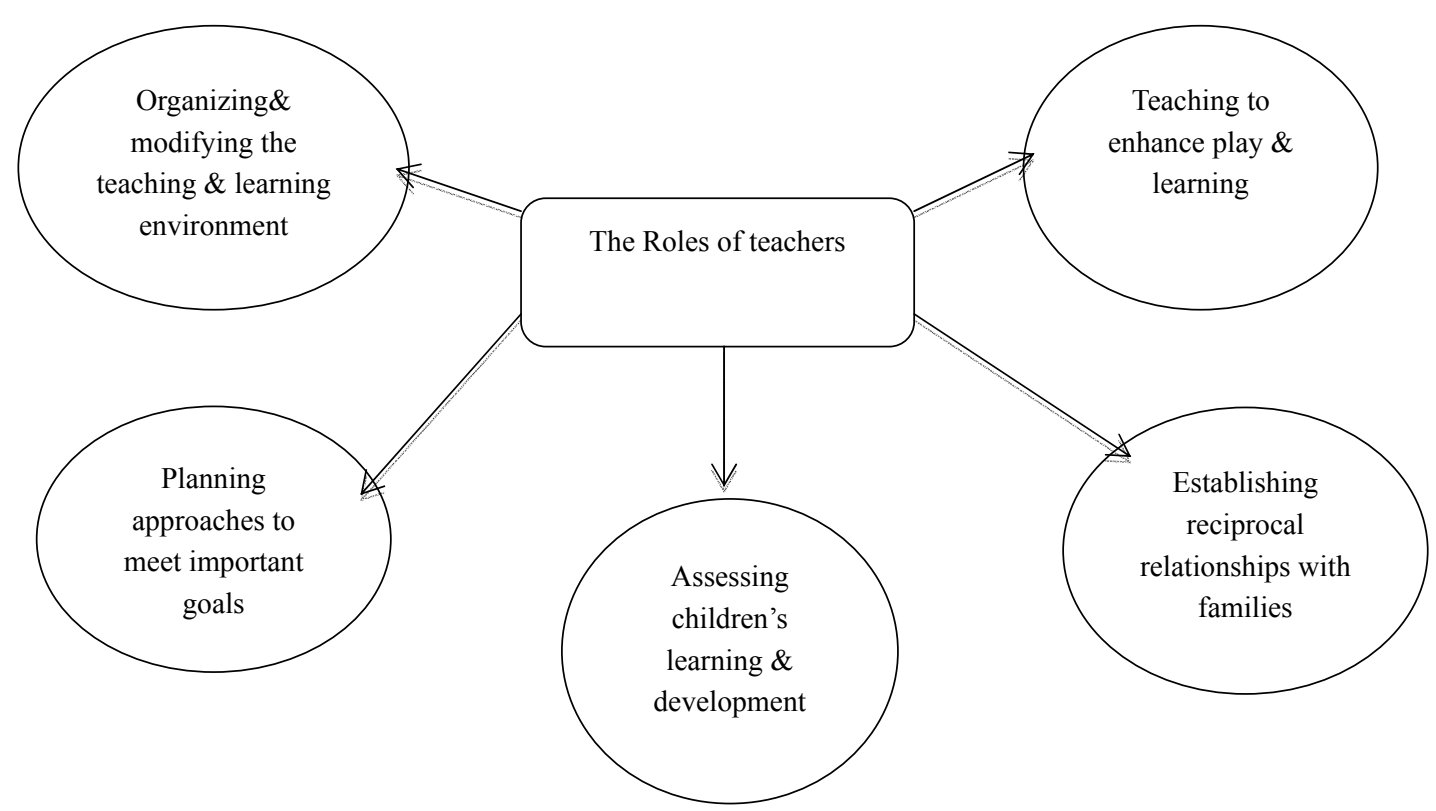

Figure 1. The roles of teachers

\subsection{Towards Integrated Pedagogies}

Teachers or practitioners are expected to use different pedagogical approaches, which include adult-led and child-initiated activities, as well as "free" and structured play. Adult led activities include structured approaches with defined learning intentions that are applicable to the whole class or to groups (Wood, 2010). However, there are varying degrees of flexibility for children in how tasks are presented, and what responses are expected. The teachers can harness the qualities of play by developing integrated pedagogical approaches, which combine the benefits of adult-directed and child-initiated activities (Wood, 2010). The following model in Figure 1 represents this integration, and allows for elements of playfulness in child-initiated and teacher-directed activities. The model adopts the perspective that play in early childhood settings is always structured to varying degrees by the indoor and outdoor environment, the curriculum, the adult: child ratio, the resources available, the rules, and the values, beliefs and practices of the adults (Wood, 2010).

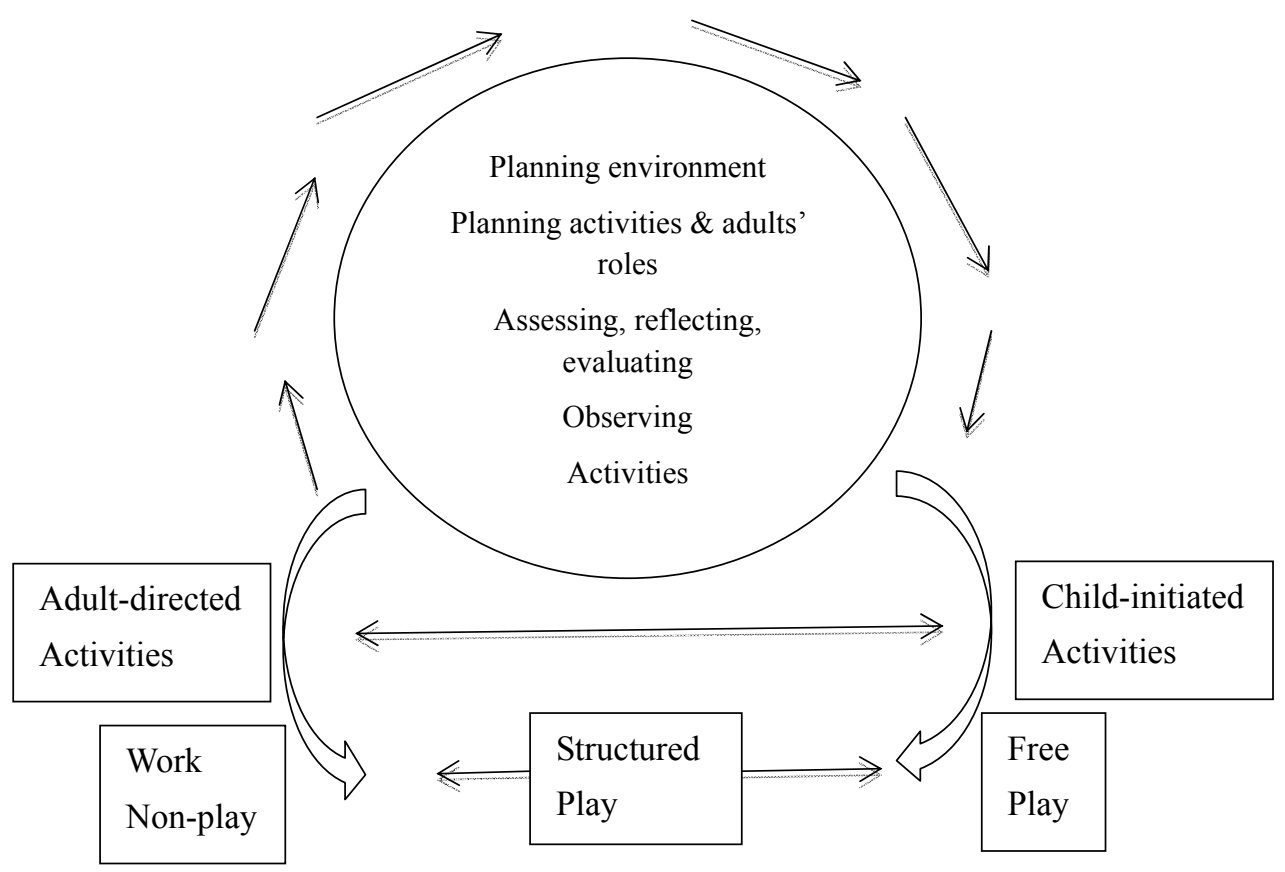

Figure 2. A model of integrated pedagogical approaches (adapted from Wood, 2010, p. 21) 
The pedagogical orientation uses the cycle of planning the play/learning environment, interacting with children in a range of activities, observing, reflecting, evaluating and returning to further planning. The aim is to ensure a flow of information about children's play and learning from two pedagogical zones-adult-and child-initiated activities, both of which have contrasting but complementary forms of adult and child involvement, co-constructive engagement, and pedagogical strategies. In the child-initiated zone, freely chosen play activities are closest to 'pure play' (Wood, 2010). Children are free to choose an adult teacher as co-player or peer-peer negotiation, refer to an adult help, and set their own goals. The children will exercise choice, control and imagination.

While in the structured play zone, Wood (2010) suggested adult-directed activities may engage children in playful ways with curriculum content: there may be some elements of imagination, but limited choice and control for children. For example, a teacher may ask children to solve mathematical problems in the context of imaginary situations. Teachers can respond to their observations of child-initiated play by providing enrichment activities, making props for play, or extending the challenge.

\section{Results}

\subsection{Interview Data Elicited by Interview Questions with Teachers, Administrators and Parents}

In Preschool 1, teachers, administrators and parents were interviewed in order to develop a deeper understanding of the value they placed on play and learning through play. Following is a summary of their responses.

\subsubsection{Play, Meaning and Concept}

Teachers' views

At Preschool 1, in order to develop a deeper understanding of the play concept, teachers were asked to explain their views of its roles and values. In summary, the teachers' responses revealed that they did recognize play as having a great value in learning and as playing a significant role in advancing children's construction of understanding and in promoting child development. They were clear in their opinions about its defining quality and what it does for children. As one teacher stated:

Children actually learn through playing because playing is their nature. It is the way they acknowledge the world and environment. They will be able to expand their knowledge on language and numbers. For example, the game, "Pukul berapa Datuk Harimau?" (What time is it, Mr. Wolf?) teaches them the language and the number concept. As Imam Al Ghazali said, playing can expand children's self-nature besides give health and strength to their body and muscles. When they play, for example running, they develop their psychomotor skills.

Both teachers responded positively when they were asked about the contribution of play to children's development as well as its roles and significance in their worlds. The teachers appeared to readily accept that young children need to play, that play is intrinsically motivated and supremely satisfying for them.

To me... children when they play they can explore things and it is a comprehensive basis suitable for children at this stage. For example, six year-old children can experience excitement by playing, compared to learning that must be stressful. Playing is in children's nature, so, it is their daily activity; they just want to play all the time. Therefore, when conducting teaching and learning, we let them play and we can create one activity to allow them to learn and they get something out of it.

Play is considered to be fun and enjoyable, whereas work is labeled as serious, rigid and even stressful activity for young children.

Uhhhmm ... for the activity just now, I focused on learning, and there were no play activities. Before this, they learnt while playing, but not for this one. My target was for them to read. So, I used the drilling technique.

She added:

Actually, the way the children learn is different from one another. Some children could use their imagination while playing with an airplane toy, for instance, but some other children just simply play with it. But at the same time they learn. On the other hand, learning is a process to gain knowledge and skills through learning, training and thinking. Children are focused when they learn; meanwhile, when they play they seem enjoy.

It is interesting to uncover the knowledge or information teachers have concerning the contribution of play to child development. Finding out what teachers know about this may add richer information and become important points in examining teachers' understanding of the concept of play itself

The interview results with the four preschool administrators underscore the fact that respectively they have different perceptions and interpretations about how play may be translated in classroom practice. The 
perceptions of the administrators in Preschools 1 and 2 were similar in that they recognized play as having great value and playing a major role in constructing learning and child development within an educational context. In contrast the administrator of Preschool 4 argued that play must be based on more academic concepts and be well planned and structured educational play; neither should play be allocated for a long period of time. Meanwhile, in Preschool 3 what the administrator understands about play completely differed from that of her teachers.

Table 1. Teachers' definitions of play

\begin{tabular}{ll}
\hline Definition & Teachers/school administrators (n) \\
\hline Play, roles \& values (enjoyment, fun, amusement) & 7 \\
Contribution to child development & 7 \\
Play then work (specific educational program) & 5 \\
\hline
\end{tabular}

\subsubsection{Play Allocation}

\section{Teachers' views}

The teachers in Preschool 1 preferred learning that built on from play. The explanation below describes how one teacher organizes play during teaching and learning.

After I conducted the play activity, I continued with learning activities. For instance, after they play the fishing alphabet card game, the children return to class. We hold a continuation activity from the fishing game, like learning syllables and reading words.

Thus play was identified as an activity that could really only be used if it connected with the topic or subject under investigation.

Information on how space and 'corners' for play were used was collected from the teachers when they discussed classroom management. During these discussions teachers had to describe the physical layout of their classroom and discuss what provisions they made for play. The aim was to see if there was any link between how each teacher approached or provided play opportunities in the curriculum and how this was reflected in the classroom setup. The teachers here provided the following information:

Right now we are dividing the space into several corners. There is the science and technology corner, the art and craft corner, the imaginary/role play corner and the reading corner. For example, in the reading/language corner, we have put a bookshelf or small table. So, when they finish their activity they can sit there and read. In the science and technology corner, we have put a computer and a radio as well as tasks for the children to do. These centers or corners should be meaningful for children instead of being for display purposes only. We want them to hold and explore the work of their friends and so on.

This view is supported by the research of Wood (2010), who writes in relation to play, the main emphasis is on play as educational practice-a means of learning, progress and achievement, including preparatory skills training (for example, playing with manipulative materials improves fine-motor skills and leads to the coordination needed for pencil control and writing). In terms of power relationships, practitioners control what forms of play are allowed, and how much ownership and control children have, but with limitations on time, resources and space (p. 13).

Table 2. Number of teachers and parents who promote children's play in given ways

\begin{tabular}{ll}
\hline Definition & Teachers/ school administrators (n) \\
\hline Purpose of allocating play in teaching and learning & 6 \\
Provide play activity and equipment & 12 \\
Provide Space and corners for play & 6 \\
Participate in and encourage play & 5 \\
Provide time and opportunities & 12 \\
Not necessary to do anything & N/A \\
\hline
\end{tabular}

The teachers in all the case studies reported valuing play as a medium and foundation for learning. During my 
observations a similar situation in Preschools 1 and 2 emerged where play was identified and deployed as an alternate or interval activity if it was linked to a topic of a particular subject. In Preschool 3 and 4 teachers reported preferring to teach in a formal way and only in certain situations (when they deserved reward) and activities did they deploy play during teaching and learning. Meanwhile, the teachers in Preschools 1 and 2 were well planned and structured in their teaching lesson plans, in contrast to the teachers in Preschools 3 and 4 where they only briefly explained what they were going to teach or plan for the day.

\subsubsection{Teaching Style and Approaches}

There are many closely linked aspects influencing teachers' approaches to educating young children. Of course there are many reasons why children are grouped together for schoolwork, mixed ability groups are for example common, as are friendship groups. Indeed the use of group work is one aspect of teaching that demonstrates a teacher's beliefs and philosophy that underpin their teaching style.

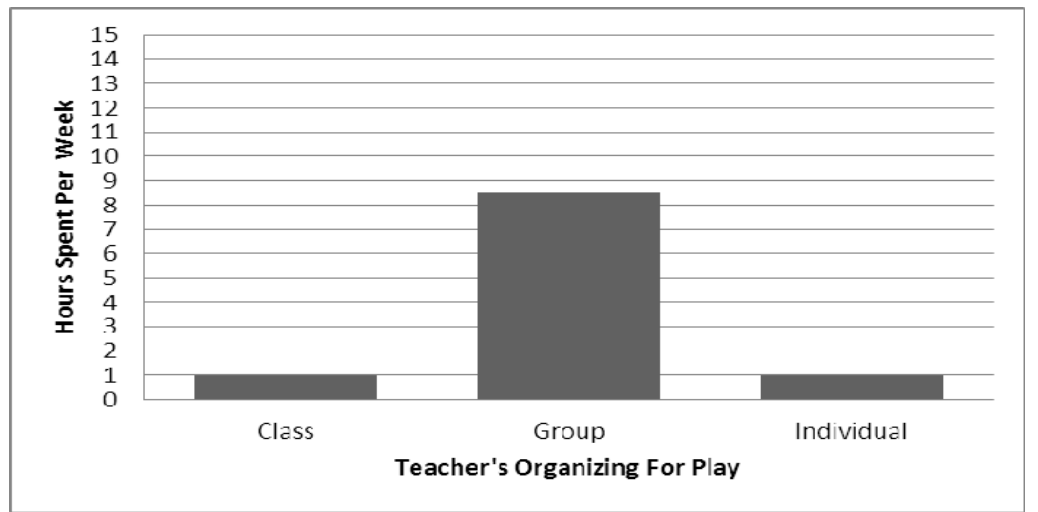

Figure 3. Teacher's organization of class for play over the observation period

Figure 3 shows the amount of time allocated to different class settings as organized by the preschool teacher in Preschool 1. She arranged for one hour of play where the children operated as a class, eight and a half hours in group play and one hour for individual play. In all of the six types of play observed by me, the teacher favoured putting children in groups. This demonstrated the suitability between her advocated teaching style and what she practiced. Because in organizing learning activities she connected play with formal learning "play in passing" and grouped the children in ways that made it easier for the teachers to instruct them and show examples of how to complete each activity. Most of the rhymes sessions especially during circle time, involved the teacher organizing the children into a whole class activity. The teacher led the song and movement activities.

As mentioned above, there are reasons why the preschool teacher organized the children as they did especially for play activities. The teachers' comments reflect their philosophy of teaching and the types of play, for example

Because for me it depends on the types of play. As during free play, the children might be involved in solitary and parallel play.

Furthermore, Teacher 1 elaborated on her current teaching style,

When I asked them to count beetles toys, this was mostly an individual activity even though they were sitting in a group.

Regarding the approaches used, the two teachers from Preschool 1 consistently claimed that the children learn through fun and play activities and they applied a thematic approach sometimes using project-based experiments when delivering the syllabus content. Timetable arrangements are based on particular areas of child development such as cognitive development, language development, aesthetic development, and social development. All of this work demonstrates a strong connection with how Vygotsky viewed quality learning and his theoretical stance places great emphasis on the importance of the adult's role in enhancing a child's thinking and doing and as an outcome of social support (Brennan, 2008).

\section{Teachers' Views}

To me, children when they play they can explore things and it is a comprehensive basis suitable for children at this stage. For example, six year-old children can experience excitement by playing, as compared to learning 
that is often tense. Playing is in children's nature, so, it is their daily activity; they just want to play all the time. Therefore, when conduct teaching and learning, we let them play monitored by us as teachers and we can create one activity to allow them to learn and get something out of it.

One teacher clearly described the benefits of having a focus on the overall development of children:

Through playing, children can attempt their own ideas, explore things themselves, and enhance their cognitive ability. When they see a thing, they want to touch and hold it themselves, and it is exciting for them. Actually, playing helps to strengthen the concept of learning. Basically, when they play, they can socialize with friends, develop their emotions, for example, they share things with each other. Then, they can express their feelings and strengthen their physical development.

This same teacher also highlighted how they used the National Preschool Curriculum:

For example, the 'inquiry-finding' approach can be done by doing experiments. Let's say, making soap bubbles. We give them soap and water, which seems like they are just playing, but they will actually learn something. When they mix the soap and water then they shake it, they form bubbles.

One limitation to incorporating play into the classes was referred to by the teachers as the 'overloaded' syllabus, which strongly connected to time limitations. They argued that there was just no time:

Sometimes, we created an activity that needed to run for a longer time than before. But, if we rushed that could cause us to lose the target and focus.

Sometimes, preschool teachers are uncertain about parents' demands:

Some parents disagreed with the approach of learning through play that we used in preschool classroom. Actually, this type of parent does not really understand this concept. They think the children simply playing, whereas we are actually teaching the children at the same time. I did hold a meeting with parents to explain the concept of playing. Usually, parents watch their children from afar and they don't know for sure, yet they don't bother to ask, they just know how to blame teachers. This issue is ongoing even happening to the Year One teachers.

Other factors that impacted related to limited play materials, equipment, and or resources:

Materials are not enough. For example, some of the Lego equipment is broken and there is not enough. If we compare at private preschool, the materials are complete in a set.

Furthermore this problem is very much linked to budget and finance:

The budget is definitely the problem. The lack of equipment is due to budget constraints, if not, we would have bought the materials.

Teachers in Preschools 1 and 2 claimed the children learnt through fun and they applied a thematic, scaffolded, and play-based approach. Sometimes they used project-based experiments when delivering syllabus content. They also claimed they used all the approaches recommended by the preschool curriculum (see Table 3).

In Preschool 4, one teacher was not interested in deploying play, preferring to teach in a formal way. Teachers here emphasized other areas of specialization and therefore, the time allocated to play was very limited. Play was limited to chants and rhymes and physical activity periods. Here the administrator admitted that her teachers saw play as something to fill in time between academic learning lessons.

Table 3. Teaching style $\&$ approaches (theory into practice) as reported by teachers

\begin{tabular}{lll}
\hline Definition & Academic way (Teachers-n) & Fun in learning (Teachers-n) \\
\hline Teachers' organization of play & 5 & 5 \\
Teaching \& learning activity approaches used & 3 & 5 \\
\hline
\end{tabular}

\subsubsection{Curriculum Aspects and Teacher Professionalism}

Teachers' Views

One teacher commented on her understanding of the preschool curriculum and that on the whole, it is vital to examine what actually needs to be done in the classroom. According to this teacher:

Right now, we are using the National Preschool Standard Curriculum. There are two kinds of modules, the first is the basic core and the second is the thematic module. The basic module offers languages, Malay language, 
English, Tamil and Chinese. And the thematic module concerns the roots. To me, the National Preschool Standard Curriculum is excellent because it does not only focus on thematic learning but it also emphasizes the " $4 M$ "-reading, writing, counting and reasoning. The reasoning method is the most interesting because we can expand learners' potential through their observations and reasoning in science activities.

Administrator's Views

The administrator felt that greater cooperation between teachers and parents could be advantageous. Yet, sometimes there were conflicts between the administrators' or teachers' perspectives regarding a child's needs and those of the parents and what they were seeking. In some situations, they have to support the child while in another situation they have to support the parents as well:

The curriculum is written because it came from the Ministry. For example, after we came back from courses, all parents were called for the briefing regarding the changes and revisions of the curriculum. Everything has been informed. Sometimes the target is hard to reach. This is because we depend on the parents, some of them are less concerned about their children's education, but there are parents who cooperate.

Pressure from the parents and State Education Department authorities for greater inclusion of academic activities was widely felt both by the administrators and their teaching staff:

We are too exam-oriented. These can influence parents in a way that they might force their children to achieve high scores, especially at the primary school level. For the preschool level, parents expect preschool teachers to teach in a formal way so as to make sure their children can read and write by the time they enter Year One.

Table 4. Problems and constraints as reported by teachers and administrators in deploying play

\begin{tabular}{ll}
\hline Definition & Teachers (n) \\
\hline Overloaded syllabus problem & 4 \\
Budget \& limited finances & 4 \\
Demand of Education State Department & 2 \\
Limited equipment, rigid schedules \& inadequate space & 3 \\
Demands from parents for academic achievements & 4 \\
Play caused discipline problem & 2 \\
\hline
\end{tabular}

Teachers in Preschools 1 and 2 had similar opinions about the curriculum in that they perceived the National Preschool Curriculum to be appropriate, suitable and relevant to the children's age and stage of development. However the teachers in Preschool 2 described the curriculum and the school timetable as restrictive in the three-hour session set aside for incorporating play activities into teaching. The lack of play materials reflected budgetary problems and put pressure on teachers to improvise with the implementation of play.

In contrast, Preschool 3's teachers formulated their own modules while also abiding by the National Preschool Curriculum and combined this with other modules, namely the Smart Reader and Anakku modules. As a researcher, I interpreted this approach as one in which play in the preschool classroom is not to be implemented in all aspects as an underlying approach to learning but is based purely on the needs of a particular subject.

The teachers in Preschool 4 emphasized that they were familiar with the curriculum content advocated by the MOE and the preschool's administrator's recommendations to implement it. However, one of teachers had her own approach to teaching and her own method of teaching.

Teachers in Preschools 1 and 2 admitted that sometimes they used workbooks as tools of enrichment, whereas some of them disagreed with using them. This situation was different from that in Preschools 3 and 4, where teachers based their teaching on workbooks and exercise books and where drills in workbooks became a necessary activity in classroom practice. A common feature regarding all teachers in every preschool setting was the suggestion to their administrators to make provision for their professional development through workshops and courses or on-the-job training to improve their skills and understanding of the curriculum for children. All the administrators agreed that cooperation between teachers and parents would be advantageous. This was strongly supported by the administrator in Preschool 1 in terms of demands and pressure from the parents, the wider community and the Department of Education. Table 4 shows 5 out of 8 teachers in all settings said that they integrated play into the curriculum, and the rest said they preferred to teach in an academic and traditional way. 
Some parents emphasized that as parents they had to be clear about their objectives in sending their children to preschool. The children also have to learn the reasons for doing certain things at school; this reflects socialisation or moral education. With regard to the curriculum, parents on the whole proposed two conditions for learning through play; play was suitable only for younger children, but not when they are about to enter or are already enrolled in primary school. This is because learning must become more academic with much less emphasis on play activity.

Reasons that parents gave as to why they advocated a given time for play fell into three general categories. First, children do not need much playtime; they need to do other things. The emphasis here was on academics. Second, children need play as a break from work, a response that emphasized the work-play dichotomy. The third category emphasized the positive aspects of play: play was seen to have inherent value as a learning activity.

Table 5. Relationship between teachers' and parents' definitions of play and integration of play into the curriculum

\begin{tabular}{lll}
\hline Definition & Teachers (n) & Parents (n) \\
\hline Play integrated into the curriculum & 5 & 3 \\
Play as separate times or activities & 3 & 5 \\
\hline
\end{tabular}

With a disparity between the professed beliefs held by the teachers in relation to the value of play and their subsequent attitudes to the behaviour related to play, in terms of theory, there existed intent to include or exclude play. As related to the diversity in actual practice, I examined what factors accounted for the differences. The barriers for teachers in Preschool 3 and 4 were such that, though they each professed a belief in the importance of play (as reflected in Preschool 3 teachers' statement that "children need to play" and Preschool 4 teachers' statement "play is a good way to explore and encourage learning"), they had inconsistent in their attitudes regarding the behaviors related to play. Additionally, they perceived parental demand on an academic approach.

A preschool 3 teacher's statement that,

Usually children will only play with toys when they have free time. As well, they will not be too focused. When it comes to learning, the children know that they have to concentrate and follow the teacher's instructions.

This reflected an attitude that disallows play in the learning environment. They further commented that, "we want children to achieve our objective". This represented a motivation to comply with the guidelines, but who do not really understand the value of play. The administrator in Preschool 3 supports this view, reflecting that proficiency is accomplished through teacher-directed work and formal learning.

Teachers in Preschools 1 and 2 in contrast, substantiated declarations as to the value of play with a positive attitude toward creativity and movement related play. However, the demands of the Education State Department brought pressure to bear on the use of more formal methods of obtaining evidence of learning. One of the Preschool teachers commented "it depends on the teachers' approach to the students and I usually discuss with friends asking them for examples of play activities that we can share", this represents an individual who was motivated to comply with the perceived established curriculum and guidelines. What she spoke about in terms of values paralleled what she professed to incorporate within her teaching behaviors and the way she implemented play, as an interval activity within formal learning.

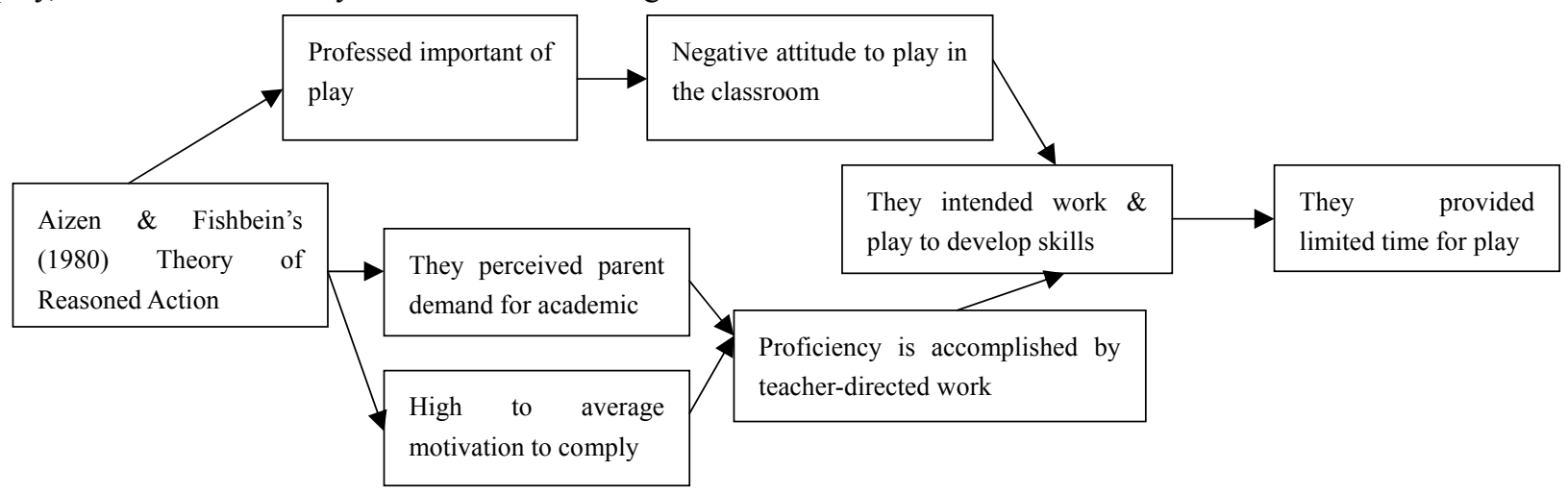

Figure 4. Theory of teachers' actions related to play in Preschool 3 


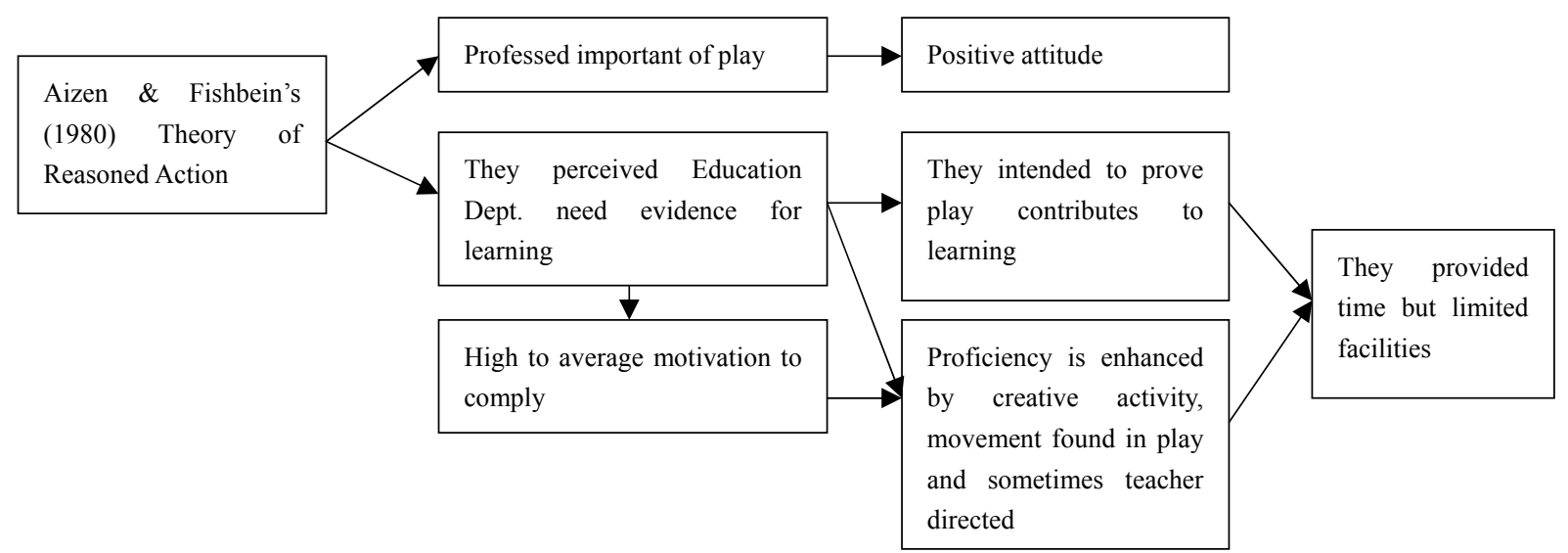

Figure 5. Theory of teachers' in Preschool 1 and 2 teaching actions related to play

\section{Conclusion}

A number of issues have emerged from the observation and interview data analysis, which enables readers to compare play implementation and non-play across the four settings and to compare the implementation of different types of play and play use. The interview analysis provided data over five conceptual themes: play, meaning and concept; play allocation; teaching style and approaches; problems and constraints; and curriculum aspects and teaching professionalism. This analysis highlights a number of constraining factors that discourage teachers from implementing learning through play.

\section{References}

Balter, L., \& Tamis-LeMonda, C. (2006). Child psychology: A handbook of contemporary issues (2nd ed.). New York: Psychology Press.

Beaty, J. J. (1998). Observing development of the young child (4th ed.). Englewood Cliffs, NJ: Prentice Hall.

Bennett, N., Wood, E., \& Rogers, S. (2009). Teaching through play: Teachers' thinking and classroom practice. Buckingham, UK: Open University Press. (Original work published 1997).

Broadhead, P. (2004). Early years, play and learning: Developing social skills and co-operation. London: Routledge Falmer. http://dx.doi.org/10.4324/9780203465257

Diaz, R. M., Neal, C. J., \& Amaya-Williams, M. (1990). The social origins of self-regulation. In L. C. Moll (Ed.), Vygotsky and education: Instructional implications and applications of sociohistorical psychology (pp. 127-154). Cambridge, MA: Cambridge University Press. http://dx.doi.org/10.1017/CBO9781139173674. 007

Economic Planning Unit. (2010). $10^{\text {th }}$ Malaysian plan 2010-2015. Kuala Lumpur: EPU.

Hewett, V. M. (2001). Examining the Reggio Emilia Approach to Early Childhood Education. Early Childhood Education Journal, 29(2), 95-100. http://dx.doi.org/10.1023/A:1012520828095

Kagan, S. L., \& Kauerz, K. (2009). Preschool programs: Effective curricula. In R. E. Tremblay, R. G. Barr, \& R. D. V. Peters (Eds.), Encyclopedia on early childhood development. Montreal, Quebec: Centre of Excellence for Early Childhood Development. Retrieved from http://www.child-encyclopedia.com/documents/BertrandANGxp.pdf

Kamogawa, A. (2010). Early childhood education in Malaysia: A comparison with Japan. Paper presented in Early Childhood Education Conference, Japan.

Ling, C. P. (1993). In K. P. Sai, L. Y. Ching, \& K. B. Boon (Eds.), Changes in the New Primary School Curriculum \& Implications for Pre-school Education in Malaysia. Fikiran-fikiran mengenai pendidikan di Malaysia, Kuala Lumpur, Malaysia: Utusan Publications \& Distributions Sdn. Bhd.

Little, H., \& Wyver, S. (2008). Outdoor Play: Does removing the risks reduce the benefits? Australian Journal of Early Childhood, 33(2), 33-40.

Roskos, K. A., \& Christie, J. F. (2010). Play's potential in early literacy development. Retrieved from $\mathrm{http}: / / \mathrm{www}$. enfant-encyclopedia.com 
Takeuchi, M. (1994). Children's play in Japan. In J. Roopnarine, J. Johnson, \& F. Hooper (Eds.), Children's play in diverse cultures (pp. 51-72). Albany, NY: State University of New York Press.

Tejima, M. (2006). Early Childhood Education for Malaysian Unification through the Malay Language \& Internationalization through English. In M. Ikeda, \& Y. Chiaki (Eds.), Preprimary education in Asia: System \& practice of curriculum. Tokyo: Akashi Shoten.

Vygotsky, L. (1978). Mind in society. Cambridge, MA: Harvard University Press.

Wood, E. (2010). Developing integrated pedagogical approaches to play and learning. In P. Broadhead, J. Howard, \& E. Wood (Eds.), Play and learning in the early years (pp. 9-25). London, New Delhi: Sage.

\section{Copyrights}

Copyright for this article is retained by the author(s), with first publication rights granted to the journal.

This is an open-access article distributed under the terms and conditions of the Creative Commons Attribution license (http://creativecommons.org/licenses/by/3.0/). 